\title{
THE EVALUATION OF THE CURRENT STATE OF EHF-SENSORS QUALITY IN THE TECHNICAL SYSTEMS AND ITS IMPROVEMENT
}

\begin{abstract}
In the article the function and the scale for the entropy evaluation of the current state of extremely high frequency (EHF-) sensors quality in the various technical systems which fits the requirements of universality and maximal independency from the human factor are offered. One may see such EHF-sensors for the analysis of the quick transformations of the biological liquids properties. It's high lighted that the available methods of the determination of technical systems' quality have essential flaws which consist in both subjectivism because the dominant role in the evaluation belongs to experts and legitimacy of providing them properties of universality which was proved by nobody.
\end{abstract}

The scheme of EHF-sensor is analyzed for which one may create an analytical model. The problem of the fields' determination at the working region of such sensor is discussed. The presented scheme is possible to use for the mathematical model and just for that part of the problem which is devoted to the transformation of the properties of the object. The results of calculation of components of electromagnetic field at the working space of EHF-sensor are discussed. One may estimate the sizes of this space. The offered function of the quality evaluation, the parameter of which is the quantity of own information of the explored sensor, provides the declared universality approach according to the principles of the information theory. The conformity to all requirements for the functions of the evaluation of the quality: continuity, monotonic and smoothness over the whole range of definition regardless of the probability distribution function, which is measured by the random value EHF-sensor was proved.

The proposed scale of the entropy evaluation of the quality fits to standard settings of the diagnostic of the technical systems and has three sub ranges which determine the state of the EHF-sensors: good state, up state, and down state. Unlike the existing psychophysical scales the offered scale has dynamic range of the evaluation so the limits of the sub ranges will automatically change depending on the regulatory and technical requirements for the state of the explored EHF-sensor. Such approach provides adaptation of the scale to specific requirements which gives a chance to evaluate the qualitative state of the object more reliably. The results of modeling of the qualitative state of the sensor are given. The possible practical application of the offered function and scale is usage in the systems of monitoring and diagnostic for determination of the current qualitative state of the explored technical system, as well.

${ }^{1}$ Candidate of Technical Sciences, IPA professor, National University of Life and Environmental Sciences of Ukraine, Kyiv, Ukraine, ychovnyuk@ukr.net

${ }^{2}$ Senior Assistant, National Aviation University, Kyiv, Ukraine

${ }^{3}$ Candidate of Technical Sciences, professor, Kyiv National University of Construction and Architecture, Kyiv, Ukraine

${ }_{5}^{4}$ Assistant, Kyiv National University of Construction and Architecture, Kyiv, Ukraine

${ }^{5}$ Candidate of Technical Sciences, assistant professor, National University of Life and Environmental Sciences of Ukraine, Kyiv, Ukraine

${ }^{6}$ Candidate of Technical Sciences, assistant professor, National University of Life and Environmental Sciences of Ukraine, Kyiv, Ukraine 
Key words: aperture, coaxial line, dynamic range of the evaluation, extremely high frequency (EHF-) sensors, the function and the scale of the entropy evaluation.

\section{Introduction}

Methods of control using electromagnetic waves of the millimetre range (extremely high frequency control) (EHF-control) have a number of advantages. These methods include non-invasiveness during the study of biological objects in vivo and the pace of measurement. The primary information is the complex dielectric permittivity $\widetilde{\varepsilon}$ which largely depends on the distribution of free water and water linked with macromolecules $[1,2]$. The velocity of creating and breaking links processes can be high making difficult the use of biochemical and other methods requiring sample preparation. EHF-methods allow to trace changes in the parameters of biological objects throughout the entire transformation period. This makes the task of adapting EHF-sensors for the study of biological objects relevant.

The determination of the EHF-sensor's transfer function is a very complicated and cumbersome task. The simplest way to solve it is to use numerical methods which are implemented by the modern software. These methods provide a vivid presentation of the mm-range electromagnetic field components' distribution for a particular sensor design. However, it is difficult to trace dependencies, to find out interrelationships using these methods. Multiple repetitions of calculations with heuristic trend determination are required. Therefore, in this case, analytical methods providing cumbersome but readable formulas are more preferable.

The purpose of this research paper is to search and substantiate at the qualitative level the type of sensor being optimal for tracing rapid transformations of biological objects. However, it is necessary to solve the problem of optimizing the structure so that it would be possible to compose its rigorous mathematical model [3].

\section{Selection of EHF-sensor type}

EHF-sensors (or sensors of electromagnetic signals/mm-waves) find more and more wide utility in various fields [4-6]. Usually, the values of the real $\varepsilon^{\prime}$ and imaginary $\varepsilon^{\prime \prime}$ parts of the complex value of investigated substance's (biological object) dielectric permittivity $\tilde{\varepsilon}$ are determined with their help. The current level of (semiconductor) EHF-electronics development (with an electromagnetic waves wavelength $\lambda=1 \ldots 10 \mathrm{~mm}$ ) makes the creation of such meters economically viable.The design of sensors [7-9] becomes more complicated, the methods for their 
description [10-12] are improved. Two types of EHF-transducers are used: guidedwave transducer and resonator transducer. The guided-wave transducer allows to measure in a certain frequency range (for example, $30 \ldots 65 \mathrm{GHz}$ ). This is an important advantage. The measurement of parameters in the frequency range provides information which is determined in this case by a linkage between water molecules and macromolecules of biological substance $[1,2]$. But the sensitivity of the guidedwave methods is significantly lower than the sensitivity of the resonator ones.

In our opinion, the most suitable type of EHF-transducer is a quarter-wave resonator $(\mathrm{QR})$ with a sensor in the form of open coaxial measurement instrumentation (aperture) (CMI) [13-15].

It has several advantages. A significant part of electric field energy is located outside the main resonating volume. Therefore, the working area can be located outside the resonator but with some loss of sensitivity. The link between the resonator field and the sample is provided via CMI which can be equipped with dielectric inserts, rings allowing to change the transfer function. The size of CMI can be significantly less than the wavelength [16-18]. Therefore, the sensor in the form of CMI can function in a wide range of frequencies and this allows to explore objects up to nanoscale ones [7, 19,20]. Another advantage of the QR is that it allows to change the operating frequency in a wide range. To do this, it is enough to change its inductive, short-circuited part $\left(\Delta z_{0}\right)$. This generally contributes to increasing the reliability of any type of indirect measurement $[4,5,16,21]$. In this case, this advantage is of fundamental nature.

The main criteria for determining the shape of the sensor's operation area can be the possibility of non-invasive in vivo sample diagnostics and the possibility of sensor parameters' analytic presentation. They are determined using the description of the electromagnetic field (EMF) components available in the operation area. The search for analytical presentations of fields is most favourable if the operation area elements coincide with the coordinate surfaces. Taking into account the above criteria, it is most rational to create a sensor in the form of CMI in a flat screen.

\section{EMF-components in the operation area}

The main oscillation mode in the QR is obtained by the TEM (transverse electromagnetic wave) transformation of a coaxial line situated near the open end. Therefore, the QR has an azimuthal component of the magnetic field $\left(H_{\varphi}\right)$, a radial component of the electric field $\left(E_{r}\right)$ and an axial component $\left(E_{z}\right)$ amplified near the exit aperture. At the qualitative level, the distribution form of EMF electrical component in the $\mathrm{QR}$, as well as its rigorous mathematical presentation in the entire 
volume of the QR, can be obtained on the basis of well known Green tensor functions, Maxwell equations for cylindrical areas [22, 23]. Given the fact that the QR has only one component of the magnetic field, it is simple to write down the solution for it. The general expression is as follows:

$$
\stackrel{\rho}{H}(\stackrel{\rho}{r}, z)=\int_{V} \Gamma^{M}\left(\stackrel{\rho}{\rho}, \rho^{\prime}\right) \cdot \stackrel{\rho}{j}^{M}\left(\rho^{\prime}\right) d v
$$

If there is the only one component of the magnetic field, then $H_{\varphi}$ is linked only with one component of the source $j_{\varphi}{ }^{M}$. Therefore, for $H(\rho, z)$, it will be enough to take one transverse component of 9 components of the Green tensor function. In the absence of variations in azimuth, it is simplified as follows:

$$
G_{n \varphi \varphi}\left(\stackrel{\rho}{\rho}, \rho^{\prime}\right)=\frac{1}{\lambda_{n} k_{n}{ }^{2}} \cdot \frac{\partial}{\partial r} \chi_{n}(r) \cdot \frac{\partial}{\partial r^{\prime}} \chi_{n}\left(r^{\prime}\right) \cdot g_{n}\left(z, z^{\prime}\right),
$$

where:

$\chi_{n}(r)$ - eigenfunctions,

$\lambda_{n}$ - norms of eigenfunctions,

$k_{n}$ - eigenvalues,

$g_{n}-$ axial component of Green function.

The $\mathrm{Oz}$ axis passes along the main axis of the CMI.

The eigenfunctions are presented by linear combinations of Bessel-Neumann functions:

$$
\chi_{n}(r, R)=\left[N_{0}\left(k_{n} r\right) J_{0}\left(k_{n} R\right)-J_{0}\left(k_{n} r\right) N_{0}\left(k_{n} R\right)\right]
$$

where:

R- area border.

If the area is not limited, then the $\mathrm{k}_{\mathrm{n}}$ series become continuous: $0 \leq k<\infty$.

If in this construction the EMF penetrates only through cross-sectional surfaces, then the magnetic currents $j_{\varphi}{ }^{M}$ are expressed by $E_{r}$ on these surfaces:

$$
j_{s}^{M}=-\left[h_{0} \times E\right]=\left\{\begin{array}{l}
-E_{r}\left(r, z=z_{i+1}\right) \\
E_{r}\left(r, z=z_{i}\right)
\end{array} .\right.
$$


where:

$i$ - ordinal number of the biological substance's intermediate layer monitored using the EMF-sensor.

In the general case, the axial components of Green functions $g_{n}$ are as follows:

$$
g_{n}\left(z, z^{\prime}\right)=\frac{\gamma_{i}^{-1}}{\operatorname{sh} \gamma_{i} \Delta z_{i}} \cdot\left\{\begin{array}{l}
\operatorname{ch} \gamma_{i}\left(z-z_{i}\right) \operatorname{ch} \gamma_{i}\left(z_{i+1}-z^{\prime}\right), \quad z<z^{\prime} \\
\operatorname{ch} \gamma_{i}\left(z^{\prime}-z_{i}\right) \operatorname{ch} \gamma_{i}\left(z_{i+1}-z\right), \quad z>z^{\prime}
\end{array}\right.
$$

where:

$\gamma_{i}-$ longitudinal constants of propagation.

For the case of unlimited area $\gamma_{i}=\sqrt{k^{2}-\widetilde{\varepsilon}_{i} k_{0}^{2}}$, where $k_{0}$-propagation number in a free space, $\widetilde{\varepsilon}_{i}-$ complex dielectric permittivity constant of the $i$ area's filling material. (For a limited area, $\mathrm{k}_{\mathrm{n}}$ is used).

The expression for $H_{\varphi}$ in the $i$ unlimited area is as follows:

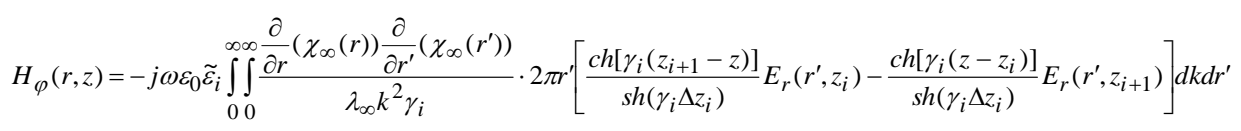

where:

$\varepsilon_{0}-$ vacuum dielectric constant, $\omega$-cyclic frequency.

If the sample is a multilayer structure, then on the layers' borders, all sources can be brought to the source at the aperture. To do this, it is necessary to write $H_{\varphi}$ above and below of each border and equate them on the basis of border conditions $H_{1 \tau}=H_{2 \tau}$. Based on $E_{1 \tau}=E_{2 \tau}$, the sources at the borders are equal. The limits of integration and eigenfunctions $\chi$ are also similar. Therefore, the integrands for $H_{\varphi}\left(r, z_{i+1}-0\right)$ and $H_{\varphi}\left(r, z_{i}+0\right)$. must be similar. Based on this, we obtain the linking coefficients between $E_{r}\left(r^{\prime}, z_{i+1}\right)$ and $E_{r}\left(r^{\prime}, z_{i}\right)$ in the form of a "ladder" structure:

$$
K_{i}=\operatorname{csh}\left(\gamma_{i} \Delta z_{i}\right)\left\{\operatorname{cth}\left(\gamma_{i} \Delta z_{i}\right)+\frac{\tilde{\varepsilon}_{i+1} \gamma_{i}}{\tilde{\varepsilon}_{i} \gamma_{i+1}}\left[\operatorname{cth}\left(\gamma_{i+1} \Delta z_{i+1}\right)-\frac{\operatorname{csh}^{3}\left(\gamma_{i+1} \Delta z_{i+1}\right)}{K_{i+1}}\right]\right\}^{-1} .
$$


As for the aperture, you can set the distribution $E_{r}\left(r^{\prime}, z_{1}\right)$ as $E_{r}=U_{0} \cdot\left(r^{\prime}\right)^{-1}$, where the voltage is linked as $U_{0}=U_{a} / \ln \left(R_{2} / R_{1}\right)$, with the voltage between the conductors forming the aperture $U_{a}$ and this will allow to determine the value of the equivalent capacitance CMI, and hence, the transfer characteristic of the sensor [24]. This will be sufficient in most practical applications.

It is possible to use more rigorous, but more cumbersome approach, which includes solving an integral equation with respect to $E_{r}\left(r^{\prime}, z_{1}\right)$ [25]. $E_{r}\left(r^{\prime}, z_{1}\right)$ [25]. But in both cases, the field inside the sample is calculated according to the above procedure.

\section{Analysis of EMF distributions in the CMI}

A layered sample can be an approximate presentation of a biological object during the period of its properties' transformation due to the physical or chemical factors' effects acting from the side opposite to the screen. But to create a rigorous mathematical model, it is necessary to eliminate the influence of processes at the edges of the sample. To do this, the radial size of the sample must be substantially larger than the area where the main energy of the aperture's electromagnetic field is concentrated.

At a qualitative level, the distribution visualization of EMF components near the aperture will allow to evaluate insert's required dimensions. To do this, the simplest version of the calculation specifying the field sources in the aperture plane $E_{r}\left(z_{1}\right)=U_{0} \cdot\left(r^{\prime}\right)^{-1}$. is used. In this case, the expressions for the distributions $H_{\varphi}, E_{r}$ and $E_{z}$ are simplified to integrals with respect to wave numbers:

$$
\begin{aligned}
& H_{\varphi}(r, z)=-j \omega \varepsilon_{0} \tilde{\varepsilon}_{1} U_{0} \int_{0}^{\infty} \frac{\left[J_{0}\left(k R_{1}\right)-J_{0}\left(k R_{2}\right)\right] J_{1}(k r)}{\gamma_{1} \exp \left[\gamma_{1}\left(z-z_{1}\right)\right]} d k, \\
& E_{r}(r, z)=-U_{0} \int_{0}^{\infty} \frac{\left[J_{0}\left(k R_{1}\right)-J_{0}\left(k R_{2}\right)\right] J_{1}(k r)}{\exp \left[\gamma_{1}\left(z-z_{1}\right)\right]} d k, \\
& E_{z}(r, z)=U_{0} \int_{0}^{\infty} \frac{\left[J_{0}\left(k R_{1}\right)-J_{0}\left(k R_{2}\right)\right] J_{0}(k r)}{\gamma_{1} \exp \left[-\gamma_{1}\left(z-z_{1}\right)\right]} k d k .
\end{aligned}
$$


The simplest conditions are chosen for calculations: aperture dimensions $R_{1}=1 \mathrm{~mm}, R_{2}=2 \mathrm{~mm}, \quad$ voltage $U_{0}=1 \mathrm{~V}, \quad$ QR's operating frequency $\omega=2 \pi \cdot 10^{10} \mathrm{GHz}$, insert's dielectric permittivity $\widetilde{\varepsilon}_{1}=3+i \cdot 0,001$. The sample size is substantially bigger than the aperture size.

The calculations made using a PC showed that the distributions of the electromagnetic field's magnetic component $H_{\varphi}(r, z)$ and the radial component of the CMI's electric field $E_{r}(r, z)$,comply with the following laws: 1) the main energy of the fields is concentrated in the area adjacent to the aperture of $1 \ldots 2 \mathrm{~mm} ; 2$ ) the electric field's radial component is more concentrated. The electric field's axial component $E_{z}(r, z)$ in the radial direction damps also rapidly, but this process is slower along the $\mathrm{Oz}$ axis.

As the dielectric permittivity effect on the resonator's EMF is transmitted through the electric field component, the external impact on the sample from the side opposite to the screen can be evaluated at the distance of $0.8 \ldots 1.0$ of the aperture's outer radius.

In general, it can be concluded that the effective interaction area dimensions correspond to the aperture dimensions. The reduction of the aperture dimensions has no theoretical limitations, so the sample dimensions, and hence, (in the case of the outer factors' influence) the velocity will be limited only by the technological capabilities and properties of the biological object.

\section{Entropy approach to the biological objects' physiological signals analysis}

The most part of the biological objects' physiological signals (PS) include deterministic, stochastic and chaotic components. At the same time, traditional spectral and correlation methods for analyzing the PS allow to evaluate only deterministic and stochastic processes. In this regard, during the last ten years, neurocognitive researches are increasingly turning to the mathematical instrumentation for the nonlinear dynamics evaluation, in particular, to the use of entropy for the evaluation of normal and pathological neurodynamic systems [28, 30, 34].

An unequivocal definition of the term "entropy" does not exist, but more often it is considered as measure of indeterminateness, measure of chaos in a dynamic system. Lately, a number of different evaluations has been implanted for a quantitative evaluation of the time series' entropy. These approaches can be represented by two groups: spectral entropy and insertion entropy. The spectral entropies $(\mathrm{SpE})$ evaluate changes in the amplitude component of the PS's energy spectrum (determined using 
the EHF-sensors) using the amplitude components at each frequency of the power spectrum as calculations of entropy probabilities. On the other hand, the insertion entropy provides the information on how the PS oscillates with time comparing the time series with themselves at certain time delay intervals [34] and making possible to study the PS from the point of view of the nonlinear dynamics theory. In neurocognitive studies, the most common types of entropy calculated for PS are Kolmogorov-Sinai entropy, approximate entropy, selective entropy and multiscale entropy.

Spectral Entropy $(S p E)$ is calculated for the spectrum of the signal obtained using the discrete Fourier transform. Then, using the Shannon function, a set of values is determined corresponding to the obtained frequency components of the PS's power spectrum. The greater the Shannon entropy, the more distant is the system's ordered state, the maximum Shannon entropy being reached when the probabilities of all frequency components occurrence are equal, in other words, the system states are equiprobable [28]. $S p E$ is used to evaluate the functional state. Based on the assumption that a biological object being at rest (in other words, the object is in the unexcited state), the PS's power spectrum becomes narrower compared to its spreading during an active excitation of the biological object. As a consequence, it is expected that structures with a high level of activity will be characterized by a high level of Shannon entropy. Today, spectral entropy is most prevalent in PS's automated monitors and is used to determine the different stages of biological objects' de-excitation.

Shannon static entropy is extended to a dynamic system in the form of Kolmogorov-Sinai Entropy (KSE), which is defined as the rate of loss of information about the state of the dynamic system over time and is considered as one of the most important characteristics of deterministic chaos. KSE values set the evaluation of the information loss rate allowing to interpret it as measure of the system's "memory" or a measure of the rate of "forgetting" the initial conditions. The smaller $K S E$ value is, the more deterministic system is and vice versa, the bigger $K S E$ values are, the bigger system's stochasticity is and as a result, the prediction of its future states is poor. The role of $K S E$ for nonlinear systems is similar to the role of the autocorrelation function for linear systems. In particular, KSE is associated with Lyapunov exponents characterizing the dynamic system's stability [27]. The formula for calculating KSE is based on Shannon entropy formula, in other words, Kolmogorov-Sinai entropy is defined as asymptotic increment of uncertainty for an infinitely small size partition. But in practice, $K S E$ is usually evaluated using Lyapunov exponents, or it is evaluated as approximating $K_{2}$ value through the correlation integral [29]. The $K S E$ evaluation algorithm provides for stationary long time series (35 - 45 seconds of artifact-free PS fragments with a sampling frequency 
of at least $400 \mathrm{~Hz}$ ), therefore $K S E$ has a limited application for analyzing the PS of biological objects of various nature in the monitoring mode of these PS.

That is why a modified KSE evaluation algorithm known as Approximate Entropy (ApEn) is proposed. It can be calculated for short PS's fragments (1000 samples) and is noise-resistant. The ApEn is a measure of the irregularity/predictability of finite-length time series [32]. However, ApEn values sharply decrease with the PS's fragment length increasing. In order to overcome this deficiency, the Sample Entropy (SampEn) was developed which is also KSE, but is determined on the basis of correlation entropy and not using Shannon entropy [33]. The above types of entropy quantitatively determine only the regularity (predictability) of time series on a single scale. However, there is no direct correlation between regularity and complexity. So, not fully predictable (for example, periodic) signals with the minimal entropy or completely unpredictable (for example, uncorrelated random) signals with the maximal entropy are really complex because they can be described very compactly. There is no single definition of the dynamic system's complexity. Intuitively, the complexity is due to a significant structural variety including correlations on several space-time scales. This system complexity can be quantitatively determined using the Multiscale Entropy (MSE) which is calculated on the SampEn basis and takes into account correlations appropriate for the PS on several time scales. The MSE allows to differentiate a noise and significant complexity of a signal and is also able to detect temporal correlations over long distances allowing to determine the presence of "memory" effects in the dynamics of the main signal and the complexity of the space-time systems of neurocognitive processes [31].

The entropy approach offers to the neuroscience a wide range of tools for determining brain's neurodynamic systems but it requires further development of the physiological interpretation of the obtained results.

Taking into account the importance of dielectric materials in the microwave equipment (microwave range), a wide variety of methods for measuring the dielectric permittivity is used. The resonance method is considered as the most common and accurate [35], but its use is limited to the centimeter wavelength range. During the transition to the millimeter and sub-millimeter range, quasi-optical methods are used. Devices built on various interferometer modifications basis [36, 37] provide basically high accuracy but they are excessively complex for solving problems.

The method of dielectric plate's transmission and reflection coefficients measuring has a moderate accuracy and sufficient simplicity [38]. During the formation of the reflected wave, the interference of reflections from the front and rear edges of the dielectric plate takes place. As a result, the reflection curve depends on such parameters (except the angle of incidence), such as the radiation frequency, 
plate thickness. Moreover, this dependence is nonmonotonic due to interference. Such nonmonotonicity occurs if the plate thickness $(d)$ is much less than the absorption length, i.e. $k \cdot \kappa_{0}^{\prime \prime} \cdot d<<1$, where $k$-wave vector, $\kappa_{0}^{\prime \prime}$ - the dielectric susceptibility of the plate material in the longitudinal direction (i.e. the direction of electromagnetic wave propagation in the plate). The fig. 1 shows the rated dependences of the monochromatic wave's reflection coefficients on the dielectric permittivity with the plate thickness $d=1,0 \mathrm{~mm}$ and $d=2.0 \mathrm{~mm}$ and frequency $v=78 \mathrm{GHz}$.
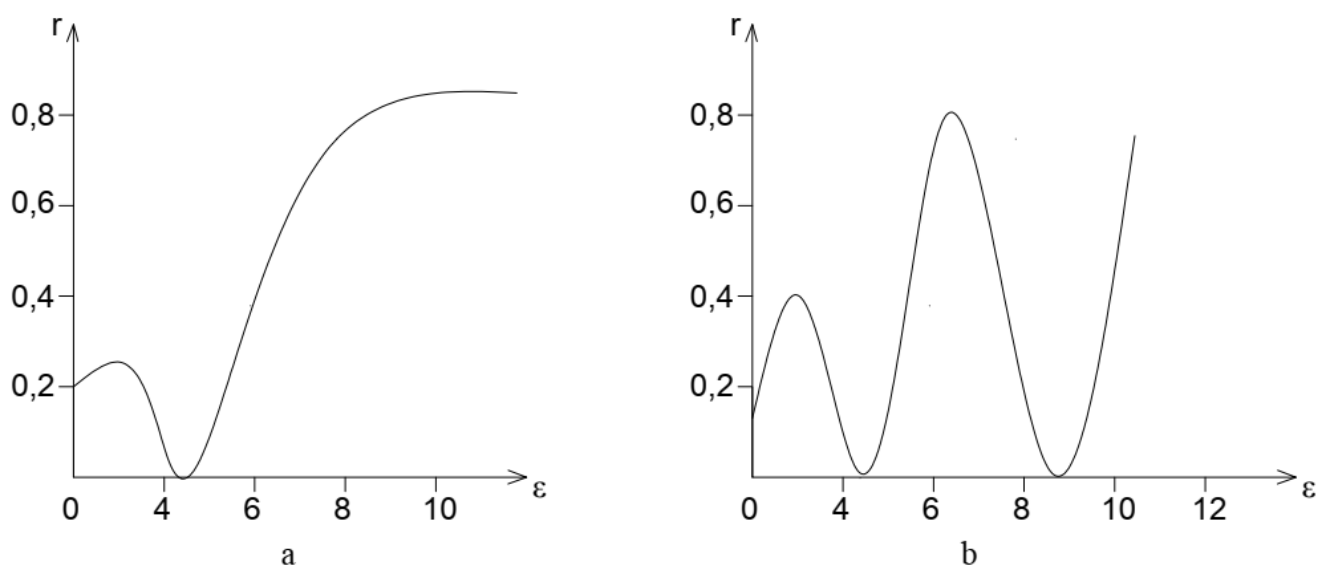

Fig. 1. The dependence of the reflection coefficients on $\varepsilon$ with the frequency $v=78 \mathrm{GHz}: a$ plate thickness $d=1.0 \mathrm{~mm} ; b$ - plate thickness $d=2.0 \mathrm{~mm}$

The curves are calculated using formula:

$$
r=\left|\frac{\left(1-\eta^{2}\right) \cdot\left\{\exp \left[-0.2 I \pi d \cdot v \cdot \sqrt{\varepsilon-\zeta^{2}} / 3\right]-\exp \left[0.2 I \pi d \cdot v \cdot \sqrt{\varepsilon-\zeta^{2}} / 3\right]\right\}}{\left((1+\eta)^{2}\right) \cdot \exp \left[-0.2 I \pi d \cdot v \cdot \sqrt{\varepsilon-\zeta^{2}} / 3\right]-(1-\eta)^{2} \cdot \exp \left[0.2 I \pi d \cdot v \cdot \sqrt{\varepsilon-\zeta^{2}} / 3\right]}\right|^{2} .
$$

where:

$v$ - radiation frequency $(\mathrm{GHz})$,

$\zeta$ - cosine of the angle of incidence;

$\eta=\sqrt{\varepsilon-\zeta^{2}} / \varepsilon \sqrt{1-\zeta^{2}}$ when the polarization of the electric intensity vector on the plane is perpendicular to the plane of incidence.

The presented graphs shows that for materials with the value of $\varepsilon \sim 7 \ldots 10$, it is better to use for the first "adjustment" measurement a plate of smaller thickness (for larger thicknesses, the multiple-valuedness may occur when calculating the 
dielectric permittivity with respect to reflection coefficient). In gradually increasing the thickness of the plate, the accuracy of determining the dielectric permittivity can be increased (due to a sharper dependence of the coefficient when larger thicknesses are used). If the dispersion is small $(k \cdot d \cdot \partial \varepsilon(\omega) / \partial \omega \cdot \Delta \omega=1)$, then the value of $\varepsilon$ can be determined by measuring the reflection coefficients for different frequencies using the same plate thickness.

Thus, it is obvious that the method for determining the dielectric permittivity using quasi-optical method with the possibility of varying the measurement accuracy by choosing the steepest sections of the dependence gives sufficient/acceptable accuracy for application in the problem of determining bound water layers $(\varepsilon \approx 2 \ldots 6)$ in capillary-porous colloidal environment.

The fig. 2 shows the dependence of $r(v)$ in the frequency range $(55 \ldots 78) \mathrm{GHz}$ for plates with the thickness (1...2) mm. Experiments confirm this dependence obtained by theoretical calculations.

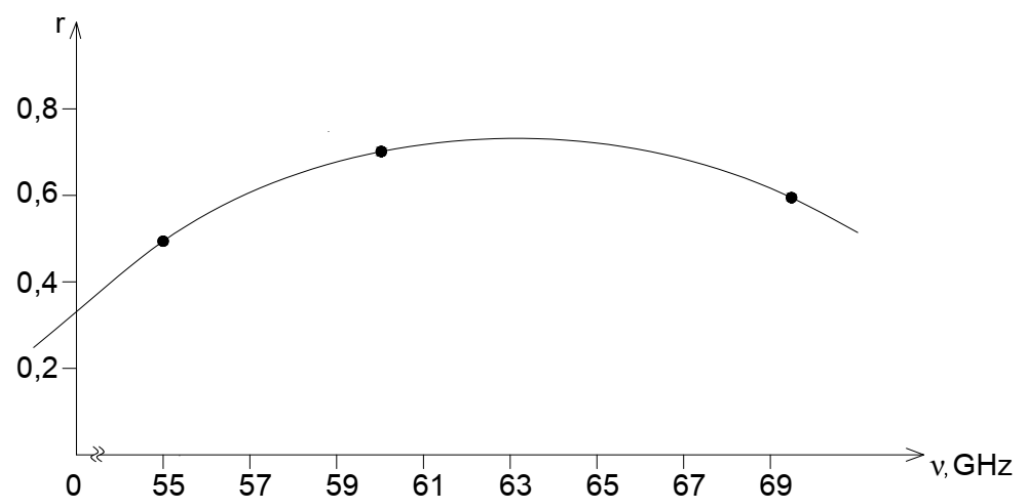

Fig. 2. The dependence of the reflection coefficient (r) on the frequency of a monochromatic electromagnetic wave of millimeter range (v) incident on the plate with the thickness

$$
d=(1 . .2) \mathrm{mm} \text {. }
$$

\section{Conclusions}

1. The performed analysis corresponds to real resonator transducers and has a practical value. The analytical presentation enables to quantify the basic parameters of the sensor already at the preliminary design stage. This is necessary to simplify the stages of specific meters modeling and designing.

2. For an analytical model of the biological substance transformation process, the selected sensor circuit allows to completely carry out all the stages of theoretical calibration of the EHF- sensor. 
3. The model evaluation was carried out for operating frequencies of $10 \ldots 60$ GHz. It is to be noted that the reduction of the operating frequency will not have a fundamental impact on results. Therefore, it is useful to evaluate the operating area for a frequency close to the free water relaxation frequency. The linkage between the water and macromolecules of biological substance will result in decreasing of the real part of the dielectric permittivity and relaxation frequency. In this case, the change of quality factor and frequency of these parameters is no less important informative parameter than the shift of the operating frequency. Together, these factors will provide the most informative measurements and high-quality operational characteristics of EHF-sensors.

4. Biological objects' physiological signals obtained using EHF-sensors include deterministic, stochastic and chaotic components. The entropy approximation allows to determine and quantify such signals as non-linear dynamics signals. An overview of the main types of entropy evaluations used, in particular, in neurocognitive researches of biological objects is presented. The following types of entropy are most productive and informative: Spectral Entropy, Kolmogorov-Sinai Entropy, Approximate Entropy, Sample Entropy, Multiscale Entropy. A physiological interpretation of various types of entropy for neurocognitive researches of biological objects (brain) is given.

\section{Bibliography}

[1.] Shhegoleva T.Ju. Gidratnoe okruzhenie i struktura makromolekul // Uspehi sovremennoj biologii. 1996. T. 116. C. 700-714.

[2.] Shhegoleva T.Ju. Issledovanie biologicheskih objektov $\mathrm{v}$ millimetrovom diapazone radiovoln. K.: Naukova dumka, 1996. 182s.

[3.] Panchenko A.Yu., Slipchenko N.I., Borodkina A.N. On the development of a practical technique of theoretical calibration of resonant sensors for near-field microwave diagnostics // Telecommunication and Radio Engineering. 2014. V. 73, No. 15. P. 13971407.

[4.] Hyde M.W., Havrilla M.J. A broadband, nondestructive microwave sensor for characterizing magnetic sheet materials // IEEE Sensors J. 2016. V. 16, No. 12. P. 47404748.

[5.] Kempin M., Ghasr M.M., Case J., Zoughi R. Modified waveguide range for evaluation of stratified composites // IEEE Trans. Instrum. Meas. 2014. V. 63, No. 6. P. 1524-1534.

[6.] Kaatze U. Techniques for measuring the microwave dielectric properties of materials // Metrologia. 2012. Vol. 47, No. 2. P. S91-S113. 
[7.] Hyde M.W., Havrilla M.J., Bogle A.E. Nondestructive Determination of the Permittivity Tensor of a Uniaxial material Using a Two-Port Clamped Coaxial Probe // IEEE Trans. Microwave Theory and Technique. 2016. Vol. 64, No. 1. P. 239-246.

[8.] Cenanovic A., Schramm M., Schmidt I. Measurement setup for non-destructive complex permittivity determination of solid materials using two coupled coaxial probes // IEEE MTT-S Int. Microw. Symp. Dig. 2011. P. 1-4.

[9.] Hyde M.W. et al. Nondestructive electromagnetic material characterization using a dual waveguide probe: A full wave solution // Radio Science. 2009. Vol. 44, No. 3. P. 10-14.

[10.] Alanen E., Lahtinen T., Nuutinen J. Variational Formulation of Open-Ended Coaxial Line in Contact with Layered Biological Medium // IEEE Transactions on biomedical engineering. 1998. Vol. 45, No. 10. P. 1241-1247.

[11.] Huang R., Zhang D. Analysis of open-ended coaxial probes by using a two-dimensional Unite-difference frequency-domain method // IEEE Trans. Instrum. Meas. 2008. Vol. 57, No. 5. P. 931-939.

[12.] Maftooli H., Karami H.R., Sadeghi S.H.H., Moini R. Output signal prediction of an openended coaxial probe when scanning arbitrary-shape surface cracksin metals // IEEE Trans. Instrum. Meas. 2012. Vol. 61, No. 9. P. 2384-2391.

[13.] Poumaropoulos C.L., Misra D. A Study on the Coaxial Aperture Electromagnetic Sensor and Its Application in Material Characterization // IEEE Transaction on instrumentation and measurement. 1994. Vol. 43, No. 2. P. 111- 114.

[14.] Blackham D.V., Pollard R.D. An Improved Technique for Permittivity Measurements Using a Coaxial Probe // IEEE Transaction on Instrumentation and Measurement. 1997. Vol. 46, No. 5. P. 1093-1099.

[15.] Gregory A.P., Clarke R.N. Dielectric metrology with coaxial sensors // Meas. Sci. Technol. 2007. No.18. P. 1372-1386.

[16.] McLaughlin B.I., Robertson P.A. Miniature open-ended coaxial probes for dielectric spectroscopy applications // J. Phys. D: Appl. Phys. 2007. No.40. P. 45-53.

[17.] Nozokido T., Bae J., Mizuno K. Scanning Near-Field Millimeter-Wave Microscopy Using a Metal Slit as a Scanning Probe // IEEE Transaction on Microwave Theory and Technique. 2001. Vol. 49, No. 3. P. 491-499.

[18.] Panchenko A.Yu. Modeling a small aperture resonator type microwave meter of substance parameters // Telecommunication and Radio Engineering. 1998. Vol. 52, No. 8. P. 118-121.

[19.] Wen Mingming. Ch. Liu, Panchenko A. Yu., Slipchenko N.I. Evaluation of influence of microwave radiation sensor in the form of an open-end of the coaxial line on its metrological characteristics // Telecommunications and Radio Engineering. 2015. Vol. 74, No. 15. P. 1355-1366.

[20.] Lju Chan, Panchenko A. Ju., Slipchenko N.I., Zajchenko O.B. Blizhnepolevoj koaksial'nyj sensor otkrytogo tipa. Ocenka prostranstvennoj razreshajushhej sposobnosti 
izmeritel'noj apertury // Vestnik NTU KPI. Serija Radiotehnika. Radioapparatostroenie. 2017. Vyp. 71. S. 17-24.

[21.] Hosseini M.H. Heidar H., Shams M.H. Wideband Nondestructive Measurement of Complex Permittivity and Permeability Using Coupled Coaxial Probes // IEEE Transactions on Instrumentation and Measurement. 2017. Vol. 66, No. 1. P. 148-157.

[22.] Panchenko B.A. Tenzornye funkcii Grina uravnenij Maksvella dlja cilindricheskih oblastej // Radiotehnika: Vseukrainskij mezhvedomstvennyj nauchno-tehnicheskij sbornik. 1970. Vyp. 15. S. 82-91.

[23.] Tai C.T. Dyadic Green's functions for a coaxial line // IEEE Trans. of Antennas and Propagation. 1983. Vol. 48, No. 2. P. 355-358.

[24.] Gordienko Ju. E., Panchenko A. Ju., Far R.S. Priblizhenie zadannogo polja v zadachah opredelenija harakteristik rezonatornyh SVCh - datchikov aperturnogo tipa // Radiotehnika: Vseukrainskij mezhvedomstvennyj nauchno-tehnicheskij sbornik. 1998. Vyp. 107. S. 93-103.

[25.] Lju Chan, Panchenko A. Ju., Slipchenko N. I., Zajchenko O.B. Koaksial'nyj sensor otkrytogo tipa. Integral'noe uravnenie jelektricheskogo polja $\mathrm{v}$ ploskosti apertury // Vestnik NTU KPI. Serija Radiotehnika. Radioapparatostroenie. 2017. Vyp. 69. S. 11-16.

[26.] Kolmogorov A. Ob entropiji na edinitzu vremeni kak metricheskom invariante avtomorfizmov // Doklady AN SSSR. 1959. T. 124. S. 754-755.

[27.] Koroljov O.L., Kussij M.Yu., Sigal A.V. Primenenie entropiji pri modelirovaniji processov prinjatija reshenij v ekonomike: Monografija. Simferopol: Izdat. "ODJAK”, 2013. 148s.

[28.] Kuznetsov A.A. Metodji analiza i obrabotki EEG signalov: novie podhodji k sboru informatsiji: monografija. Vladimir: Izdanije Gos. Universiteta Rossii. 2008. 140s.

[29.] Loskutov A.Yu., Kozlov A.A., Chachanov Yu. M. Entropija i prognoz vremennich rjadov v teoriji dinamicheskich system // Izvestija visshich uchebnich zavedenij. Prikladnaja nelinejnaja dinamika. 2008. T. 17, No. 4. S. 98-113.

[30.] Mayorov O. Yu., Fritzsche M., Glukhov A.B., and oth. New neurodiagnostics technology for brain research on the basis of multivariate and nonlinear (deterministic chaos) analysis of EEG // Proc. of the 2nd European Congr. "Achievements in space medicine into health care practice and industry”. Pabst Science Publ., Berlin, 2003. P. 157-166.

[31.] Costa M., Costa M., Goldberger A.L., Peng C.K. Multiscale entropy analysis of complex physiologic time series // Phys. Rev. Lett. 2002. Vol. 89: 068102.

[32.] Pincus S.M., Gladstone I.M., Ehrenkranz R.A. A regularity statistic for medical data analysis // J. Clin. Monit. 1991. No.7. P. 335-345.

[33.] Richman J.S., Moorman J.R. Physiological time-series analysis using approximate entropy and sample entropy // Am. J. Physiol. Heart Circ. Physiol. 2000. Vol. 278. P. H2039-2049. 
[34.] Majorov O. Yu., Gluhov A.B., Fenchenko V.N., Prognimak A.B. Realizatsija metoda smeschenija s pomoschju ocenki razmerov osej attraktora po odnomernoj realizatsiji dinamicheskoj sistemi mozga // Trudi Instituta kibernetiki NANU. Vyp. 153. 2007. S. 311.

[35.] GOST 8.544-86. Otnositelnaya dielektricheskaya pronitsaemost i tangens ugla poter dielektrikov. - Moskva, 1986.

[36.] Submillimetrovaya dielektricheskaya spektroskopiya tverdogo tela // Trudyi IOFAN (Instituta obschey fiziki Akademii nauk). - 1990. - T. 25.

[37.] Krupnov A.F., Tretyakov M.Yu., Markov V.N. et al. // Proc. 3rd International symposium "Physics of millimeter and submillimeter waves MSMW'98". - 1998. - Vol. 1. - P. 115120.

[38.] Brandt A.A. Issledovanie dielektrikov na sverhvyisokih chastotah. - Moskva, 1963.

Date of sending the publication to the Editor: 15.07.2019

The date of the publication's acceptance by the Editorial Board: 03.09.2019

DOI: $10.30657 /$ qpi.2019.11.03 